\title{
013 \\ Evaluation of different cover crops on vacant areas (pottal) in mature tea plantation
}

\author{
I R Palihakkara', B G D Udesh'1, P W D Vithanage² \\ 1 Department of Crop Science, University of Ruhuna, Sri Lanka. \\ ${ }^{2}$ Didenipotha estate, Maturata plantations Ltd., Sri Lanka
}

An experiment was conducted at a low country tea plantation in Matara district to Evaluate different cover crops species for vacant areas. It was conducted during the period of January to June 2006; the selected site was 2 nd year after pruning, T.R.I 2025 that was establishing in 1980 and the field with lot of vacant areas.

Six cover crop species (Desmodium triflorum, Arachis pintoy, Desmodium heterocarp, Vetiveria zizaniodes, Crotalaria ochroleuca. Cymbopogon nardus) were selected for the experiment. The experiment followed a Latin Square Design. Trees planted in vacant areas, with the space of 6 inches for 1,2.3, spp and 8 inches for 4,5,6 spp. Data were collected one month after the establishment.

Soil nitrogen content, $\mathrm{pH}$, biomass production and soil organic matter content were measured. Weeds count was taken two weeks interval. Survey was conducted to evaluate workers preference level of the each cover crop.

There was no significant difference within the treatments in soil $\mathrm{pH}$, organic matter $\%$ and soil $\mathrm{N} \%$, but Vetiver was found to be suitable for acid soil $(\mathrm{p}>0.05)$. Organic matter added by $D$. heterocarpon, $D$. triflorum was significantly higher than other species, D. heterocarpon and Crotalaria was highly effective in improving the soil $\mathrm{N}$ among the legumes. Before the experiment soil $\mathrm{C}: \mathrm{N}$ was $7: 1$. D. triflorum improved the soil $\mathrm{C}: \mathrm{N}(10.7: 1)$ during research period.

In generally workers did not like cover crops. However they preferred legume rather than grasses. $60 \%$ of the workers selected D. triflorum as their first choice. $26 \%$ of the workers selected A.pintoy as their first choice. D. heterocarpon, $C$. ochroleuca, and $C$. nardus were selected by only $3 \%$. Workers did not select vetiver as their first choice. Dry matter production of grasses was higher than that of legumes. V. zizanioides, D. triflorum had approximately similar shoot: root ratios.

Treatments effect for weeds population was not significant ( $\mathrm{p}>0.05$ ), but A. pintoy, D. heterocarp were fast growing and suppressed the weeds than other legumes. It was concluded that workers preferred four legume species rather than two grasses. A. pintoy, D. heterocarpon, $C$. nardus can aggressively suppress the weeds. $D$. heterocarpon, $D$. triflorum were highly improved soil nitrogen and organic matter than other legumes during the research period.

Proceedings of the International Forestry and Environment Symposium 2006 of the Department of Forestry and Environmental Science. University of Sri Jayewardenepura, Sri Lanka 